\title{
Role of Non-Invasive Methods to Predict the Presence of Gastro-Esophageal Varices among the Patients Present With Chronic Liver Disease
}

\author{
Md. Mamunur Rashid ${ }^{1 *}$, Sultana Jasmin ${ }^{2}$
}

${ }^{1}$ Consultant, MBBS, BCS, FCPS, MD, Sheikh Russel National Gastroliver Institute \& Hospital, Mohakhali, Dhaka, Bangladesh

${ }^{2}$ Medical officer, Sir Salimullah Medical College (SSMC) \& Mitford Hospital, Dhaka, Bangladesh

DOI: $10.36347 /$ sjams.2020.v08i10.017

| Received: 01.10.2020 | Accepted: 12.10.2020 | Published: 17.10.2020

*Corresponding author: Md. Mamunur Rashid

Abstract

Original Research Article

Background: Liver disease particularly chronic liver disease is one of the major public health problem, accounting for significant morbidity and mortality worldwide. Among the different complications, gastro-esophageal variceal bleeding is the deadliest complications of advanced liver disease and have been described in 50\% of patients with liver cirrhosis. Moreover, the presence of gastroesophageal varices (GEV) has important implications for the prognosis and the severity of the disease. An estimate suggest that mortality due to variceal bleeding is around 20\%. Objective: The objective of this study was to determine the role of non-invasive methods to predict the presence of gastroesophageal varices among patients with chronic liver disease. Methods: It was a hospital based cross-sectional study and conducted at the Department of Gastroenterology and department of Medicine in Dhaka Medical College Hospital, for six month period. Written informed consent was taken from the subject and ethical issues was ensured. Total 146 CLD individual was selected according to inclusion and exclusion criteria. Each patient was interviewed individually by the principal investigator. All these was registered, documented and analyzed in the statistical program Statistical Package for Social Science (SPSS) version 22.0. The data was systematically described and summarized and presented through descriptive statistics. In all cases significance level will be set at $p<.05$. Findings were expressed by graph and chart whichever is relevant. Thus the study was assessed the usefulness of non-invasive methods to predict the presence of Gastro-esophageal varices among the patients who present with chronic liver disease. Results: The mean age of the CLD patients was $44.62 \pm 13.87$ years, minimum age 20 and maximum 78 years. Majority of the patients were male $78.8 \%$ and female $21.2 \%$. Male: Female ratio was $3.7: 1$. In present study clinical presentation of CLD patients were showed $82.2 \%$ patients had splenomegaly, $63.0 \%$ patients had anemia, $55.5 \%$ patients had testiculan atrophy, $53.4 \%$ patients had ascites, $48.6 \%$ patients had hyperpigmentation, $42.5 \%$ patients had leuconychia, $41.8 \%$ patients had edema, 30.1\% patients palmar erthyema, 29.5\% patients Caput Medusa, 28.8\% patients had muscle wasting, $17.8 \%$ patients jaundice, $14.4 \%$ patients had flapping, $13.7 \%$ patients ha clubbing. The presence of gastro-esophageal varices by Fibroscan at a cut off value $18.1 \mathrm{kpa}$ with sensitivity, specificity, PPV, NPV, accuracy respectively $80 \%, 87.5 \%$, 98.1\%, 35.0\% can predict the gastro-oesophageal varices (AU ROC - 82.5\%). Gastro-esophageal varices were predicted by platelet count at a cut off value $\geq 166000$ with sensitivity, specificity, PPY, NPV was $83.8 \%, 81.2 \%$, 97.3\%, 36.1\% respectively can predict the gastro-oesophageal varices (AU ROC - 89.2\%). Enlarged spleen size cutoff value $14.1 \mathrm{~cm}$ had an acceptable sensitivity $82.3 \%$ specificity, $87.5 \%$ with a high NPV 98.2\%. Conclusion: In conclusion, noninvasive strategies probably save costs and avoid unnecessary gastroscopies; however, there are a considerable number of patients undiagnosed with these methods. In our study, platelet count, spleen size and firboscan are the best noninvasive methods. These methods can be useful in our daily practice to decide which patients could avoid a gastroscopy.

Keywords: Gastroesophageal Varices (GEV), Liver Cirrhosis, Esophageal Varices (EV), Transient Elastography, Non-Invasive Predictors.

Copyright $\odot 2020$ The Author(s): This is an open-access article distributed under the terms of the Creative Commons Attribution 4.0 International License (CC BY-NC 4.0) which permits unrestricted use, distribution, and reproduction in any medium for non-commercial use provided the original author and source are credited.

\section{INTRODUCTION}

Gastroesophageal varices (GEV) is a serious consequences of portal hypertension in patients with advanced chronic liver disease (CLD) as portal hypertension is a key event in the evolution of CLD when severe fibrosis or cirrhosis develops. Once portal pressure exceeds $10 \mathrm{mmHg}$ (clinical significant portal hypertension - CSPH), patients are at risk of experiencing severe complications such as variceal haemorrhage (VH) $[1,2]$. GEV are abnormally dilated collateral veins within the wall of the esophagus and 
stomach that project directly into the lumen and are prone to haemorrhage [3]. Approximately 30-40\% of compensated cirrhotic patients develop GEV at a rate of $7-8 \%$ per year and progression from small to large varices occurs at a rate of $10 \%-12 \%$ per year [4]. VH occurs at a rate of around $10 \%-15 \%$ per year and depends on the severity of liver disease, size of varices and presence of red wale marks (areas of thinning of the variceal wall) $[5,6]$. Estimated mortality of $\mathrm{VH}$ ranges between $15 \%$ and 25\% [7-9]. Moreover, in the compensated stage of CLD median survival of the patients exceeds 12 years, it is only 1.8 years in patients who develop decompensation [10]. All over, cirrhosis of liver constitutes the fifth-leading cause of adult deaths and ranks eighth in economic cost among the major illnesses [11]. In addition, the incidence of first $\mathrm{VH}$ ranges from 20 to $40 \%$ within two years and the chance of recurrent bleeding is 30 to $40 \%$ within the next two to three days and in up to $60 \%$ within one week. Thus, the prevention of $\mathrm{VH}$ remains at the forefront of long-term management of cirrhotic patients [12]. The American Association for the Study of Liver Disease and the Baveno IV Consensus Conference on portal hypertension recommended that all cirrhotic patients should be screened for the presence of GEV when liver cirrhosis is diagnosed [13]. Although, endoscopy is the gold standard method for the diagnosis of GEV, the performance of this invasive procedure is appreciated only for the subgroup of cirrhotic patients with high risk of having GEV [14]. However, the first line techniques for diagnosis of cirrhosis and portal hypertension include physical examination, laboratory parameters, transient elastography (TE) and DopplerUS [15]. Although physical examination alone is not as much as sensitive method for detecting portal hypertension, spider naevi is independently predictive of CSPH as well as GEV [15, 16]. Similarly, progressive spleen enlargement may predict GEV formation and growth [16]. In addition, platelet count is also independently correlated with the prevalence and grade of GEV in several studies, suggesting that it could be of help in avoiding unnecessary endoscopies [14, 17]. Again, another noninvasive quantitation of liver stiffness (LS) by ultrasound based TE using Fibro Scan has revolutionary role in the early diagnosis of liver cirrhosis [18], and high values of liver stiffness at TE are strongly predictive of the presence of CSPH, as well as varices. Moreover, several studies have shown that biochemical, clinical and ultrasonographic parameters alone or together have good predictive power for noninvasively assessing the presence of GEV [12]. According to the LSPS (liver stiffness measurement $\mathrm{x}$ spleen diameter/platelet ratio score) model, patients with a cut-off $<3.5$, gastroscopy could be avoided with a negative predictive value (NPV) of $94.7 \%$ [19]. On the other hand, patients with a cut-off $>5.5$ has a positive predictive value (PPV) of 94\%. Another proposed index called Variceal Risk Index (VRI) that included as well LS, platelet count and spleen diameter and classified correctly $65.4-76.5 \%$ of cirrhotic patients [20]. Due to invasive in nature, several initiatives are noticed over the last few years to invent noninvasive methods to predict the presence of GEV. But the result of the studies are inconclusive and sometimes controversial. More recently, a sequential algorithm based on LS, platelet count and ultrasound parameters have been used in few sites. But none of these non-invasive strategies have been evaluated specifically in patients with Chronic Liver Disease. In Bangladesh, very few studies are noticed regarding this topics. Therefore the purpose of the study is to evaluate the noninvasive methods to predict the presence of GEV among the patients present with CLD.

\section{OBJECTIVES \\ General Objective}

1. To determine the sensitivity and specificity of non-invasive methods to predict the presence of gastroesophageal varices (GEV) in patients with CLD.

\section{Specific Objectives}

2. To assess the clinical characteristics of the CLD patients.

3. To assess the socio-demographic characteristics of the respondents.

4. To assess the endoscopic findings of the patients with chronic liver disease.

\section{Methodology}

It was a hospital based cross-sectional study and conducted at the Department of Gastroenterology and department of Medicine in Dhaka Medical College Hospital, for six month period. Written informed consent was taken from the subject and ethical issues was ensured. Total 146 CLD individual was selected according to inclusion and exclusion criteria. Each patient was interviewed individually by the principal investigator. All these was registered, documented and analyzed in the statistical program Statistical Package for Social Science (SPSS) version 22.0. The data was systematically described and summarized and presented through descriptive statistics. In all cases significance level will be set at $p<.05$. Findings were expressed by graph and chart whichever is relevant. Thus the study was assessed the usefulness of non-invasive methods to predict the presence of Gastro-esophageal varices among the patients who present with chronic liver disease.

\section{Knowledge on Causation}

The main causes of cirrhosis are Guha \& Iredale [21]: (1) Alcoholic liver disease (ALD), (2) Hepatitis B (HBV), (3) Hepatitis C (HCV), (4) Nonalcoholic steatohepatitis (NASH), Haemochromatosis, (6) Auto-immune hepatitis (AIH), (7) Primary biliary cirrhosis (PBC) and (8) Primary sclerosing cholangitis (PSC). The natural history of cirrhosis can be divided into a preclinical and a 
subsequent clinical phase. The preclinical phase is usually prolonged over several years; once clinical events occur, such as, ascites, encephalopathy, variceal bleeding or the development of hepatocellular carcinoma the remaining course of the disease is much shorter and usually fatal. For liver cirrhosis there still is no curable treatment available except for liver transplantation. Cirrhosis of the liver is typical for a late stage of any disease to the liver. The necroinflammation and fibrogenesis leads to pronounced distortion of the liver resulting in death unless a liver transplant is performed. The predominant causes of liver disease are excessive intake of alcohol, viral hepatitis $\mathrm{B}$ and $\mathrm{C}$, non-alcoholic fatty liver followed by a number of cases of Cryptogenic liver disease. Over time a transition from liver disease into liver cirrhosis occurs with a scarring reaction characterized by accumulation of an altered extracellular matrix rich in fibrillar collagens. The reaction is driven by a variety of inflammatory mediators such as growth factors and cytokines released by the liver tissue with hepatic myofibroblasts in a central role. The process of cirrhosis of the liver causes a slow cascade of reactions with initially no symptoms and fully compensated developing into several symptoms and decompensated [22]. A description of stages from 1-4 describes the development with no symptoms at stage 1 . At stage 2 the blood flow through the liver decreases, and the blood pressure in the portal vein increases, the blood is forced to find alternative routes through the liver. To compensate, capillarisation of sinusoids and intrahepatic shunts develops together with the possibility of oesophagealvarices characterizing stage 2 of compensated liver cirrhosis. From this stage the condition deteriorates with a rapid increase in mortality. In decompensated stages of cirrhosis both ascites and varices develops as well as reduced function of the liver resulting in jaundice, encephalopathy and hepatorenal syndrome (HRS). HRS is a complex condition of the kidneys mainly caused by peripheral arterial vasodilatation due to excessive release of nitric oxide (NO) as the portal vein pressure increases resulting in increased renal vasoconstriction. Development of HRS is detrimental for human functioning causing death within a few weeks unless the liver is replaced [23].
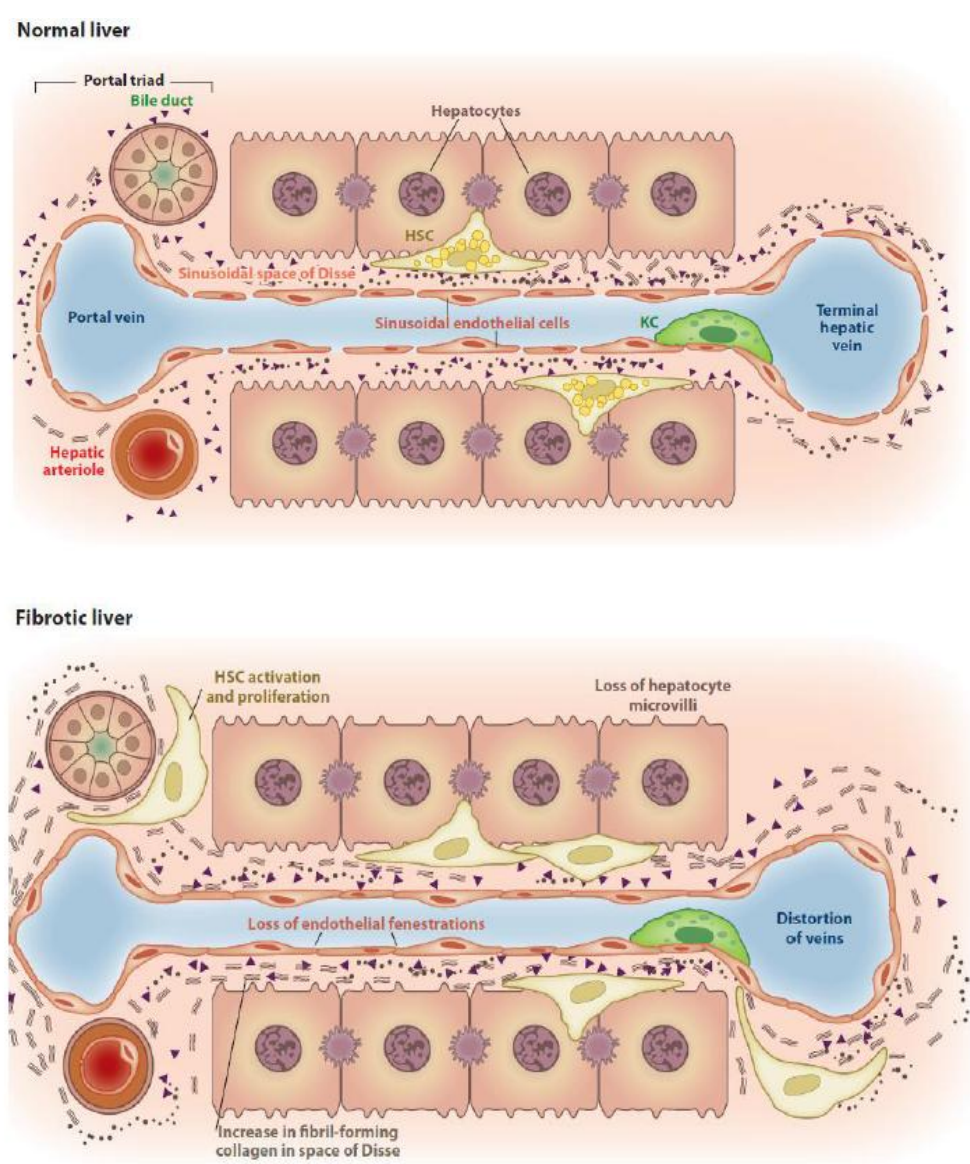

Diagrammatic features of cirrhosis of Liver

Figure-1 Features of cirrhosis. Cells of the liver lobes is divided into Parenchymal and nonparenchymal. The top part of figure shows a healthy liver part. A low density membrane ensures the metabolic exchange between Sinusoidal cells and space of Disse. Upon injury (bottom part), large amounts of extracellular matrix is secreted and deposited in the space of Disse impairing bidirectional metabolic exchange between venous blood and Hepatocytes. Figure taken from [22]. 


\section{ReSUlts ANd OBSERVATIONS}

This observational cross sectional study was conducted in the Department of Gastroenterology and Medicine, Dhaka Medical College Hospital, Dhaka from April 2018 to September 2018 to determine the sensitivity and specificity of non-invasive methods to predict the presence of gastroesophageal varices (GEV) in patients with CLD. A total of 146 patients with chronic liver disease irrespective of age and sex were selected by non-randomized purposive sampling technique.

Table-1: Age distribution of the patient $(n=146)$

\begin{tabular}{|l|l|l|}
\hline Age group (years) & No of the Patient & Percentage (\%) \\
\hline $18-30$ & 25 & 17.1 \\
\hline $31-40$ & 36 & 24.7 \\
\hline $41-50$ & 33 & 22.6 \\
\hline $51-60$ & 30 & 20.5 \\
\hline $61-70$ & 13 & 8.9 \\
\hline$>70$ & 9 & 6.2 \\
\hline Total & 146 & 100.0 \\
\hline $\begin{array}{l}\text { Mean } \pm \text { SD } \\
\text { Range }\end{array}$ & $\begin{array}{l}\mid l \\
(20-78)\end{array}$ years \\
\hline
\end{tabular}

Table-1 shows that $361(24.7 \%)$ in the age group 31-40 years followed by $33(22.6 \%)$ in $41-50$ years. The mean age of the study group was
$44.62 \pm 13.87$ years, minimum age 20 and maximum 78 years.

Table-2: Sex distribution of the patients $(n=146)$

\begin{tabular}{|l|l|l|}
\hline Sex of the patient & No of the Patient & Percentage\% \\
\hline Male & 115 & 78.8 \\
\hline Female & 31 & 21.2 \\
\hline Total & 146 & 100.0 \\
\hline
\end{tabular}

Table- 2 shows the distribution by sex. Maximum patients were male $78.8 \%$ and rest $21.2 \%$ patient was female Male: Female ratio was 3.7:1.

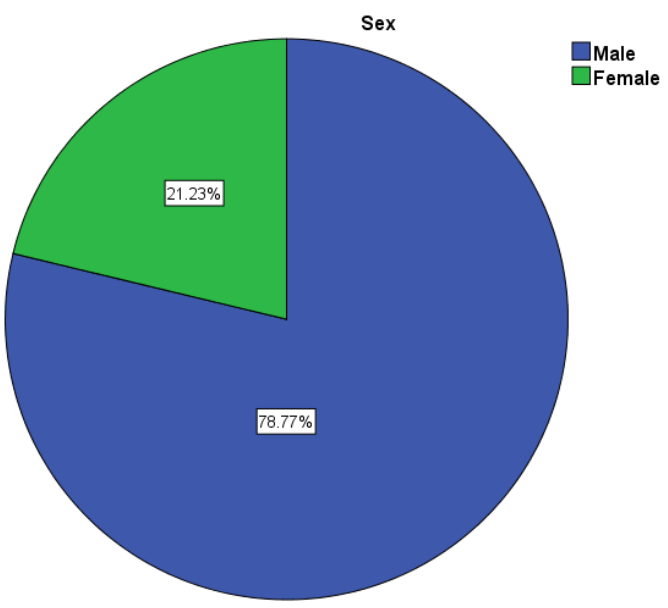

Fig-2: Sex distribution of the study patients

Table-3: Distribution of the study subjects by occupation $(n=81)$

\begin{tabular}{|l|l|l|}
\hline Occupation & No of the Patient & Percentage (\%) \\
\hline Service holder & 34 & 23.3 \\
\hline Business & 38 & 26.0 \\
\hline House wife & 28 & 19.2 \\
\hline Others & 46 & 31.5 \\
\hline Total & 146 & 100.0 \\
\hline
\end{tabular}


Table-3 showed $23.3 \%$ patients were service holder, $26.0 \%$ patients were business, $19.2 \%$ patients were housewife and $31.5 \%$ patients were other occupation.

Table-4: Distribution of the study subjects by residence $(n=146)$

\begin{tabular}{|l|l|l|}
\hline Residence & No of the Patient & Percentage\% \\
\hline Rural & 86 & 58.9 \\
\hline Urban & 60 & 41.1 \\
\hline Total & 146 & 100.0 \\
\hline
\end{tabular}

Table-4 showed that maximum patients $58.9 \%$ come from rural and $41.1 \%$ patients come from urban area.

Table-5: Distribution of the study patients by education $(n=146)$

\begin{tabular}{|l|l|l|}
\hline Education & Frequency & Percentage (\%) \\
\hline Illiterate & 44 & 30.1 \\
\hline Primary & 52 & 35.6 \\
\hline SSC & 25 & 17.1 \\
\hline HSC & 12 & 8.2 \\
\hline Graduate and above & 13 & 8.9 \\
\hline Total & 146 & 100.0 \\
\hline
\end{tabular}

Table-5 shows, distribution of the study subjects according to educational status, it was found that the maximum study subjects $35.6 \%$ primary, $30.1 \%$ were illiterate, $17.1 \%$ respondents were SSC, $8.2 \%$ patients were HSC and $8.9 \%$ patients were graduate and above.

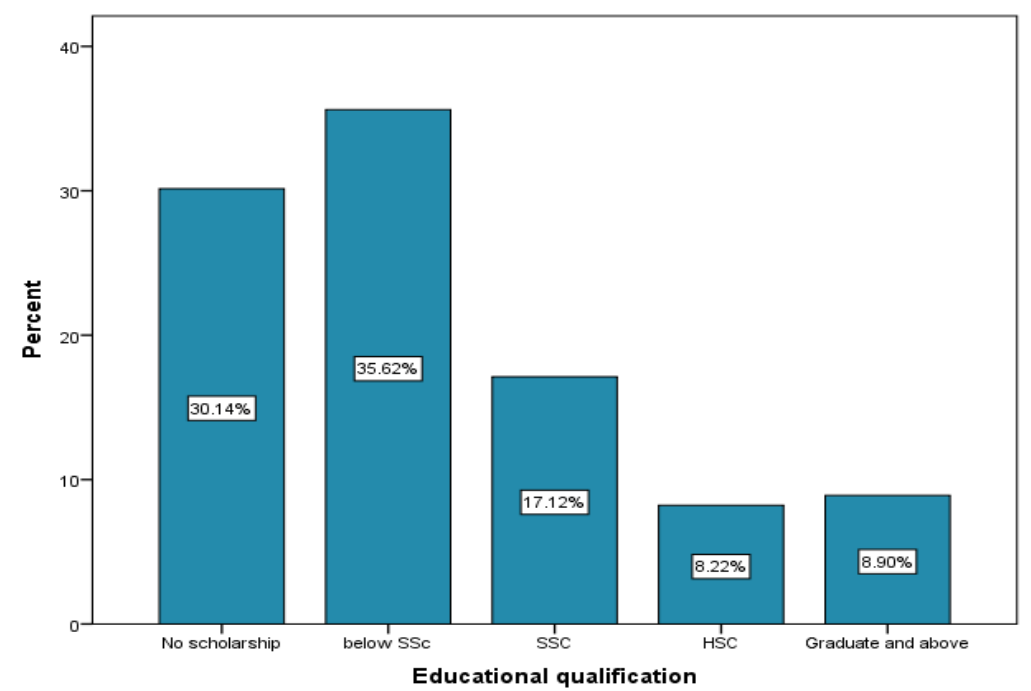

Fig-3: Bar diagram showing the educational qualification of the study subjects

Table-6: Distribution of the study patients by marital status ( $n=146)$

\begin{tabular}{|l|l|l|}
\hline Marital status & Frequency & Percentage (\%) \\
\hline Unmarried & 15 & 10.3 \\
\hline Married & 131 & 89.7 \\
\hline Total & 146 & 100.0 \\
\hline
\end{tabular}

Table-6 shows the marital status of the study subjects, maximum (89.7\%) were married and $10.3 \%$ patients were unmarried.

Table-7: Distribution of the study subjects according to socioeconomic status $(\mathbf{n}=\mathbf{3 6 2})$

\begin{tabular}{|l|l|l|}
\hline Monthly income & Frequency & Percentage (\%) \\
\hline Less than $10000 \mathrm{Tk}$. & 44 & 30.1 \\
\hline $10000-20000 \mathrm{Tk}$. & 49 & 33.6 \\
\hline $20000-40000 \mathrm{Tk}$. & 45 & 30.8 \\
\hline More than $40000 \mathrm{Tk}$. & 8 & 5.5 \\
\hline Total & 146 & 100.0 \\
\hline
\end{tabular}


Table-7 shows, distribution of the respondents according to economical status. It was found that the maximum respondents $33.6 \%$ had monthly income
10,000-20000 Tk. followed by $30.1 \%$ had monthly income of less than $10000 \mathrm{Tk}$. and $30.8 \%$ respondents had monthly income 20000-40000 Tk.

Table-8: Distribution of the study CLD patients by clinical presentation $(n=146)$

\begin{tabular}{|l|l|l|}
\hline Clinical presentation & Frequency & Percentage (\%) \\
\hline Splenomegaly & 120 & 82.2 \\
\hline Anemia & 92 & 63.0 \\
\hline Testiculan atrophy & 81 & 55.5 \\
\hline Ascites & 78 & 53.4 \\
\hline Hyperpigmentation & 71 & 48.6 \\
\hline Leuconychia & 62 & 42.5 \\
\hline Edema & 61 & 41.8 \\
\hline Palmar erythema & 44 & 30.1 \\
\hline Spider naevi & 43 & 29.5 \\
\hline Muscle wasting & 42 & 28.8 \\
\hline Jaundice & 26 & 17.8 \\
\hline Flaping tremor & 21 & 14.4 \\
\hline Clubbing & 20 & 13.7 \\
\hline
\end{tabular}

Table-8 shows clinical presentation, $82.2 \%$ patients had splenomegaly, $63.0 \%$ patients had anemia, $55.5 \%$ patients had testiculan atrophy, $53.4 \%$ patients had ascites, $48.6 \%$ patients had hyperpigmentation,
$42.5 \%$ patients had leuconychia, $41.8 \%$ patients had edema, $30.1 \%$ patients palmar erthyema, $29.5 \%$ patients spider naevi, $28.8 \%$ patients had muscle wasting, $17.8 \%$ patients jaundice, $14.4 \%$ patients had flapping.

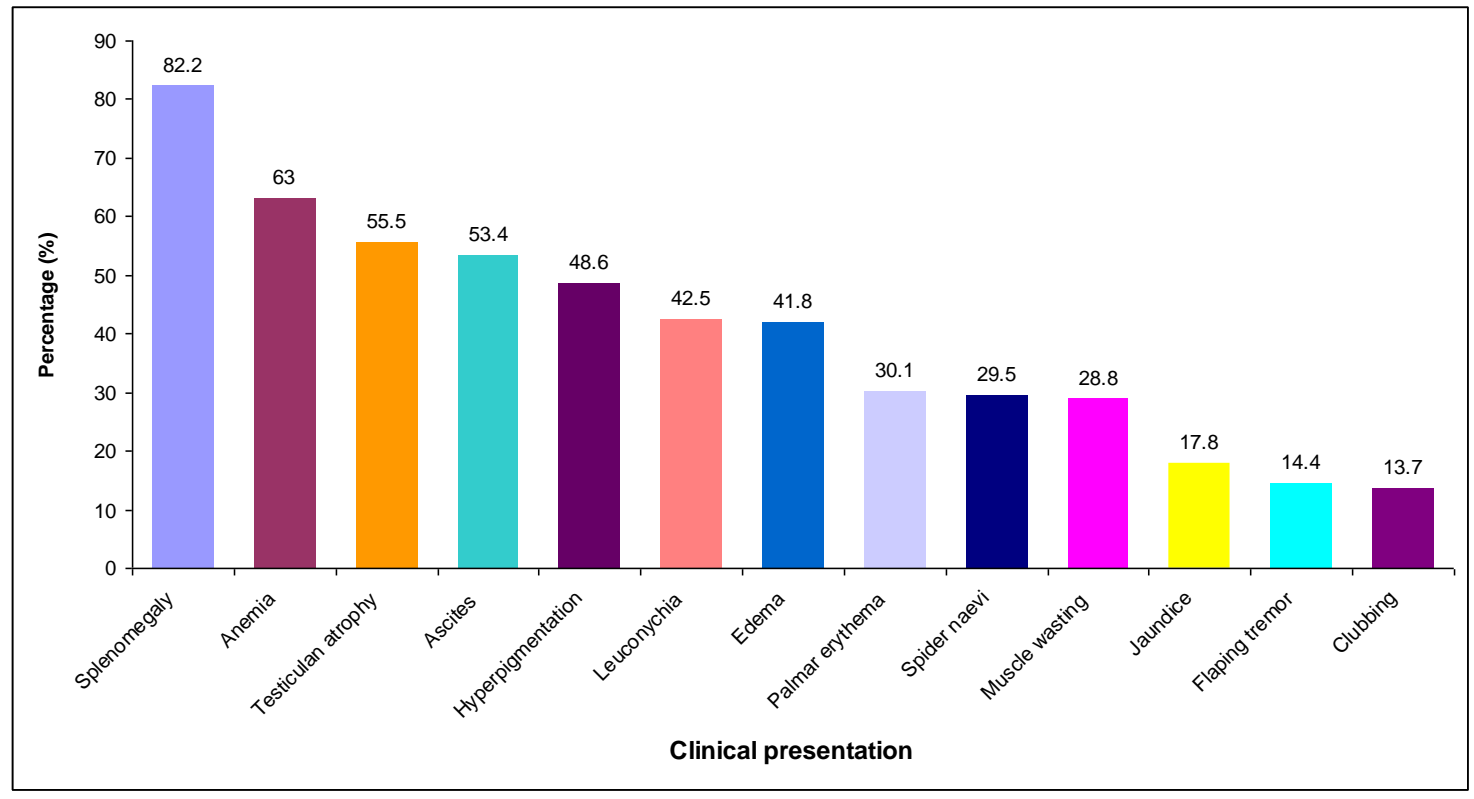

Fig-4: Bar diagram showing the clinical presentation of the study patients

Table-9: Distribution of the study CLD patients by ultrasonographic findings ( $n=146$ )

\begin{tabular}{|l|l|}
\hline Ultrasonographic findings & Mean \pm SD \\
\hline Spleen diameter $(\mathrm{cm})$ & $11.68 \pm 2.21$ \\
\hline PVD $(\mathrm{mm})$ & $10.51 \pm 1.32$ \\
\hline
\end{tabular}

Shows in mean spleen diameter 11.68 \pm 2.21 and mean PVD was found 10.51 \pm 1.32 (Table-9). 
Table-10: Distribution of the study CLD patients by endoscopy findings ( $n=146)$

\begin{tabular}{|l|l|l|}
\hline Endoscopy findings & Frequency & Percentage (\%) \\
\hline Presence of varices & & \\
\hline Yes & 130 & 89.0 \\
\hline No & 16 & 11.0 \\
\hline Total & 146 & 100.0 \\
\hline Grading of varices & & \\
\hline Grade I & 18 & 13.8 \\
\hline Grade II & 35 & 26.9 \\
\hline Grade III & 55 & 42.3 \\
\hline Grade IV & 22 & 15.1 \\
\hline Total & 130 & 100.0 \\
\hline Other findings & & \\
Congestive grastropathy & 104 & 80.0 \\
Ulcer & 5 & 3.8 \\
Polyp & 2 & 1.5 \\
Gastritis & 4 & 3.1 \\
\hline
\end{tabular}

Table-10 showed majority of the patients had varices $130(89.0 \%)$. Among 130 varices maximum Grade III $42.3 \%$ followed by Grade II $26.9 \%$, Grade IV $15.1 \%$ and Grade I $13.5 \%$. Majority of the patients had congestive gastropathy $105(80.0 \%)$, ulcer $5(3.8 \%)$, polyp $2(1.5 \%)$ and grastritis $4(3.1 \%)$.

\section{Receiver-operator characteristic (ROC) curve of} spleen size for prediction of esophageal varices

The area under the receiver-operator characteristic (ROC) curves for the esophageal varices is depicted in the following table. Based on the receiver-operator characteristic (ROC) curves spleen size had the best area under curve. Receiver-operator characteristic (ROC) were constructed using spleen size value of the patients having esophageal varices with a best combination of sensitivity and specificity for esophageal varices, which gave a spleen size cut off value of $\geq 14.1 \mathrm{~cm}$, with $82.3 \%$ sensitivity and $87.5 \%$ specificity as the value and for identifying the esophageal varices.

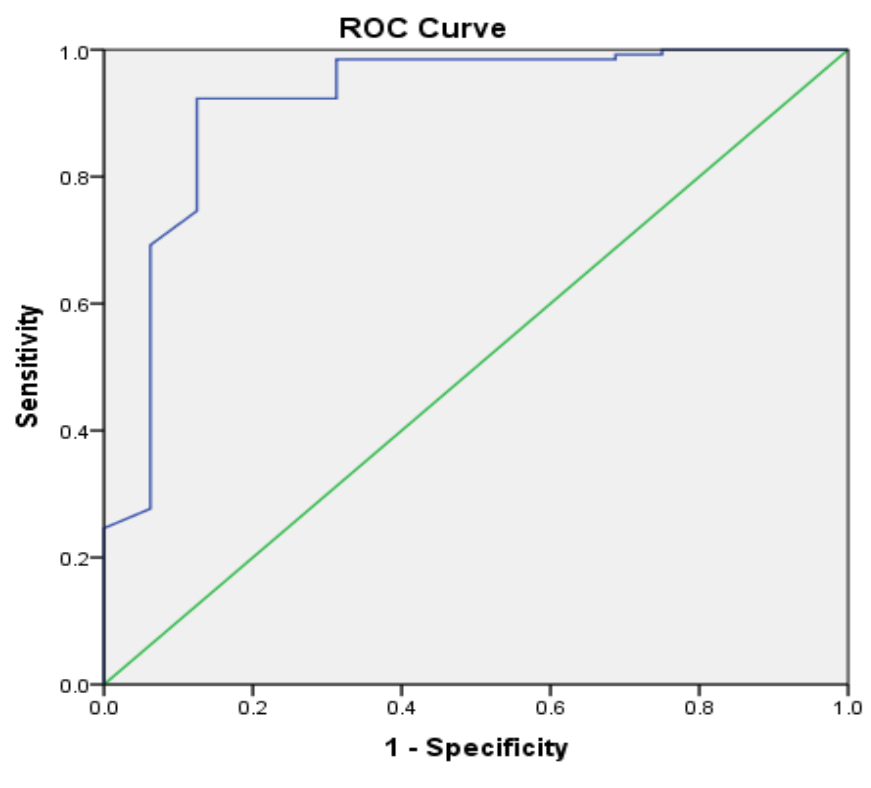

Diagonal segments are produced by ties.

Fig-5: ROC curve for spleen size in predicting esophageal varices

Table-11: Test Result Variable(s): Spleen size with varices.

\begin{tabular}{|l|l|l|l|l|l|l|l|l|l|}
\hline AUC & Std. Error & \multirow{2}{*}{ p-value } & \multicolumn{2}{|c|}{ 95\% CI } & Cut of value & Sen & Spec & NPV & PPV \\
\cline { 4 - 5 } & & & Lower & Upper & & & & & \\
\hline 0.916 & 0.047 & $<0.0001$ & 0.824 & 1.000 & 14.1 & $92.3 \%$ & $87.5 \%$ & $98.4 \%$ & $58.3 \%$ \\
\hline
\end{tabular}


Receiver-operator characteristic (ROC) curve of Platelets count for prediction of esophageal varices

The area under the receiver-operator characteristic (ROC) curves for the esophageal varices is depicted in the following table. Based on the receiver-operator characteristic (ROC) curves platelets count had the best area under curve. Receiver-operator characteristic (ROC) were constructed using Platelets count value of the patients having esophageal varices with a best combination of sensitivity and specificity for esophageal varices, which gave a Platelets count cut off value of $<126000 / \mathrm{cmm}$, with $74.6 \%$ sensitivity and $87.5 \%$ specificity as the value and for identifying the esophageal varices.

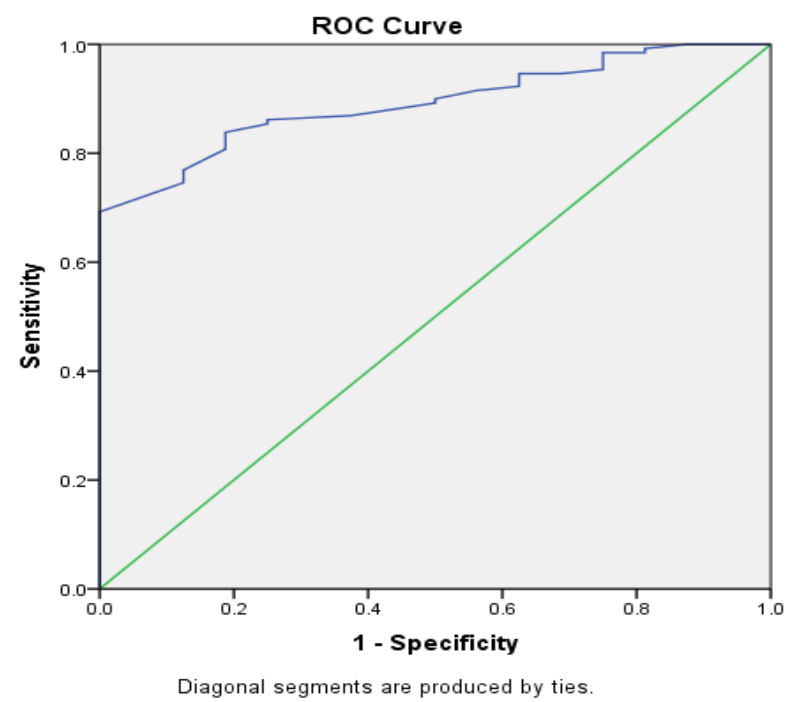

Fig-6: ROC curve for platelet count in predicting esophageal varices

Table-12: Test Result Variable(s): Platelets with varices

\begin{tabular}{|l|l|l|l|l|l|l|l|l|l|}
\hline AUC & Std. Error & p-value & $95 \%$ CI & Cut of value & Sen & Spec & NPV & PPV \\
\cline { 4 - 5 } & & & Lower & Upper & & & & & \\
\hline 0.892 & 0.030 & $<0.001$ & 0.834 & 0.950 & 126000 & $74.6 \%$ & $87.5 \%$ & $32.9 \%$ & $94.3 \%$ \\
\hline
\end{tabular}

Receiver-operator characteristic (ROC) curve of fibro scan for prediction of esophageal varices

The area under the receiver-operator characteristic (ROC) curves for the esophageal varices is depicted in the following table. Based on the receiver-operator characteristic (ROC) curves fibro scan had the best area under curve. Receiver-operator characteristic (ROC) were constructed using fibro scan value of the patients having esophageal varices with a best combination of sensitivity and specificity for esophageal varices, which gave a fibro scan cut off value of $\geq 17.85 \mathrm{~cm}$, with $81.5 \%$ sensitivity and $75.0 \%$ specificity as the value and for identifying the esophageal varices.

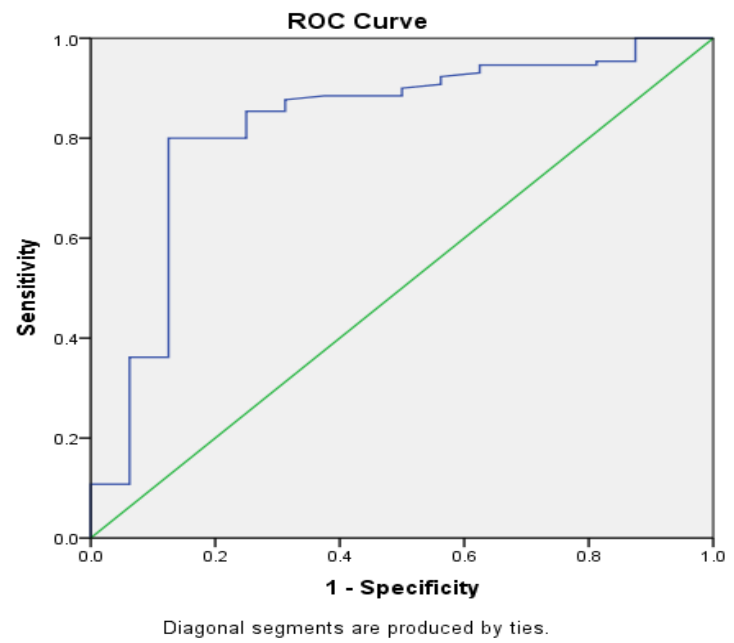

Fig-7: ROC curve for fibroscan size in predicting esophageal varices 
Table-13: Test Result Variable(s): Fibro scan with varices.

\begin{tabular}{|l|l|l|l|l|l|l|l|l|l|}
\hline AUC & Std. Error & p-value & $95 \%$ CI & Cut of value & Sen & Spec & NPV & PPV \\
\cline { 4 - 10 } & & & Lower & Upper & & & & & \\
\hline 0.824 & 0.062 & $<0.001$ & 0.703 & 0.944 & 17.85 & $81.5 \%$ & $75.0 \%$ & $33.3 \%$ & $96.4 \%$ \\
\hline
\end{tabular}

Table-14: Sensitivity, specificity, positive and negative predictive values for identifying the esophageal varices evaluated by different non-invasive methods

\begin{tabular}{|l|l|l|l|l|l|}
\hline Parameters & Cut of value & Sensitivity & Specificity & Negative predictive value & Positive predictive value \\
\hline Spleen size & 14.10 & $92.3 \%$ & $87.5 \%$ & $98.4 \%$ & $58.3 \%$ \\
\hline Fibro scan & 17.85 & $81.5 \%$ & $75.0 \%$ & $33.3 \%$ & $96.4 \%$ \\
\hline Platelets count & 126000 & $74.6 \%$ & $87.5 \%$ & $32.9 \%$ & $94.3 \%$ \\
\hline
\end{tabular}

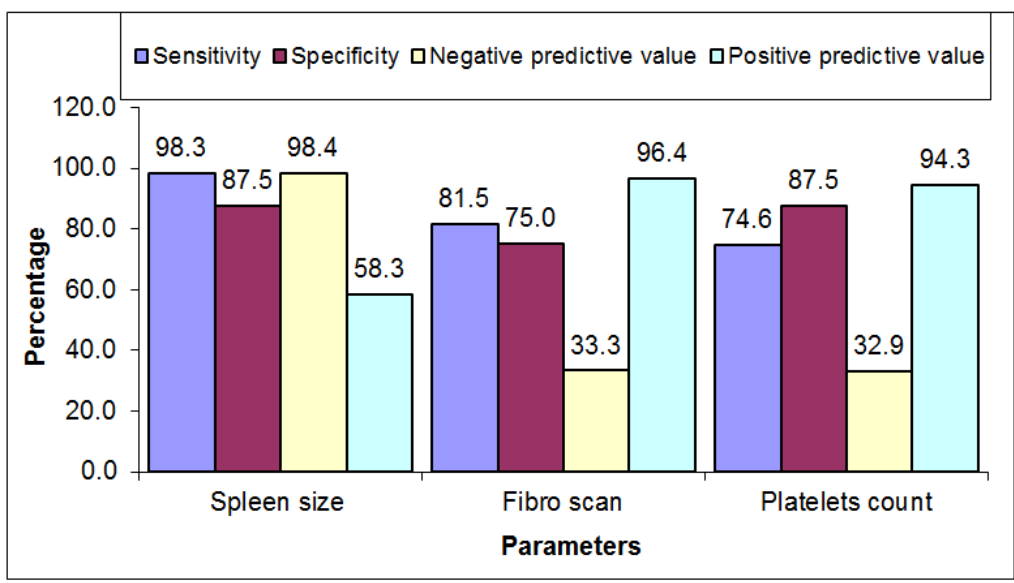

Fig-8: Bar diagram shows the Sensitivity, specificity, positive and negative predictive values

\section{DISCUSSION}

In the present study the mean age of the CLD patients was $44.62 \pm 13.87$ years, minimum age 20 and maximum 78 years. Majority of the patients were male $78.8 \%$ and female $21.2 \%$. Male: Female ratio was 3.7:1. Ahsan et al., [24], found $28 \%$ in between $46-55$ years age group which coincide with our study. $73 \%$ were male and $27 \%$ female. Male female ratio was $2.7: 1$. Mahtab et al., [25], found male female ratio of 2.97:1, which almost coincide with our study. In our study clinical presentation of CLD patients were showed $82.2 \%$ patients had splenomegaly, $63.0 \%$ patients had anemia, $55.5 \%$ patients had testiculan atrophy, $53.4 \%$ patients had ascites, $48.6 \%$ patients had hyperpigmentation, $42.5 \%$ patients had leuconychia, $41.8 \%$ patients had edema, $30.1 \%$ patients palmar erthyema, $29.5 \%$ patients Caput Medusa, 28.8\% patients had muscle wasting, $17.8 \%$ patients jaundice, $14.4 \%$ patients had flapping, $13.7 \%$ patients had clubbing. Sharma and Aggarwal [26], found splenomegaly $52 \%$, pallor $68 \% \%$, jaundice $52 \%$, pedal edema $80 \%$, spider vaevi $22 \%$, ascites $19 \%$, encephalopathy $52 \%$ in patients with cirrhosis of the liver. Mahfuzzaman et al., [27], cirrhotic patient with splenomegaly, thrombocytopenia and increase spleen had more possibility to have OV. Different studies in recent years also found similar findings [28, 29]. Several studies have reported that splenomegaly could be a good predictor of LEV for cirrhotic patients [26,
30]. In present study endoscopic findings were showed varices 130(89.0\%). Among 130 varices maximum Grade II $42.3 \%$ followed by Grade II $26.9 \%$, Grade IV $15.1 \%$ and Grade I $13.5 \%$. Out of 130 varices majority of the patients had congestive gastropathy $105(80.0 \%)$, ulcer $5(3.8 \%)$, polyp $2(1.5 \%)$ and grastritis $4(3.1 \%)$. Schepis et al., [31], reported using endoscopy, EV were detected in 63 of the 143 patients examined (44\%). Medium and large EV were observed in 28 of the 63 subjects (44\%) with EV. In present study the presence of gastro-esophageal varices by fibroscan at a cut off value $17.8 \mathrm{kpa}$ with sensitivity, specificity, PPV, NPV, accuracy respectively $81.5 \%, 75 \%, 33.3 \%, 94.6 \%$ can predict the gastro-oesophageal varices (AU ROC $82.5 \%$ ). Foucher et a1., [32], reported a cut off value $(27.5 \mathrm{kPa})$ for the presence of esophageal varices grade II/III with sensitivity $88 \%$, specificity $53 \%$, PPV $45 \%$ and NPV 90\%. Kazemr et al., [33], reported that liver stiffness measurement value < 19 kpa was highly predictive of the absence of esophageal varices grade II with sensitivity $84 \%$, PPV $47 \%$ and NPV 93\%. In contrast, Vizzutti et al. [34], found no correlation between LSM and the size of the varices. In present study the predicted gastro-esophageal varices by platelet count at a cut off value $\geq 126000$ with sensitivity, specificity, PPV, NPV was $74.6 \%, 87.5 \%$, $32.9 \%$, $94.3 \%$ respectively can predict the gastrooesophageal varices (AU ROC - 89.2\%). In accordance Pilette et al., (1999) reported that the best threshold for the diagnostic accuracy of platelet count was 
$160000 / \mathrm{cmm}$ providing a sensitivity of $80 \%$ and a specificity of $58 \%$. The ROC curve also showed that the presence of large EV is improbable if cirrhotic patients have a platelet count $\geq 260000 / \mathrm{cmm}$ (negative predictive value $\geq 91 \%$ ). In the group of patients with cirrhosis, global diagnostic accuracy was $71 \%$, and platelet count was isolated at the first step and prothrombin index at the 2nd step either for all EV or large EV Thus, platelet count appeared to be the best single marker of EV or large EV, since other markers added little information [35]. Platelet count has also been shown to be an independent marker in two other studies with multivariate analysis [28, 36, 37], reported the platelet count/spleen diameter ratio to be the only independent variable associated with presence of $\mathrm{OV}$ on multivariate analysis and identified a cut-off value of 909 , giving a PPV of $96 \%$ and NPV of $100 \%$. Sen et al., [38], found the platelet count-spleen diameter ratio of $\leq 650$ as a sensitive non-invasive marker [Area under curve (AUC) of 0.81] in HCV related cirrhosis. Cherian et al., [39], reported on univariate analysis, a platelet count-spleen diameter ratio of $\leq 666$ was significantly associated with the presence of esophageal varices in a predominant alcohol related cirrhosis subset. Llop et al., [40], demonstrated the presence of GEV was related with platelet count $(\mathrm{p}=0.02)$, TE $(\mathrm{p}=0.001)$ and spleen diameter $(\mathrm{p}=0.003)$. The multivariate analysis confirmed, although discreetly, TE OR 1.04 (IC 1.011.08). They analysed different single methods to predict the presence of GEV in patients with cACLD. Previous studies have shown that platelets are a good predictor of the presence of GEV in patients with liver cirrhosis with high sensitivity and specificity $[37,41]$. These results were confirmed partially in our study, a platelet count 260000 had a good sensitivity $74.6 \%$, specificity $87.5 \%$. In present study, enlarged spleen size cut-off value 14.1 $\mathrm{cm}$ had acceptable sensitivity $92.3 \%$ specificity, $87.5 \%$ with a NPV 98.4\%, PPV 58.3\%. Giannini et al., [37], reported spleen diameter ratios were significantly different between NOV and OV patients, spleen size (cut of point $>12.1 \mathrm{~cm}, 90.9 \%$ accuracy) had the highest accuracy for identifying patients with OV. Giannini et al., [37], used ROC curves to assess the platelet count (cut off value > 112000)/spleen diameter ratio (cut off value $>12.1 \mathrm{~cm}$ ) cut off with the best sensitivity and specificity for a diagnosis of OV (sensitivity $=100 \%$ (95\% CI 100-100); specificity $=93 \%$ (95\% CI 82-98). The prevalence adjusted positive and negative predictive values for a platelet count/spleen diameter ratio $<909$ were $96 \%$ and $100 \%$, respectively. Moreover, accuracy of the platelet count/ spleen diameter ratio cut off as evaluated by the c index was 0.981 (95\% CI 0.943-0.996). Both spleen diameter and platelet count cut offs with the best sensitivity and specificity for a diagnosis of OV. Sharma and Aggarwal [26], showed that to predict the presence of EV using simple and non-invasive tools like clinical examination for the presence of a palpable spleen and platelet count with a fairly high degree of accuracy. Thus, these two measures could accurately predict the presence or absence of EV in nearly $70 \%$ of patients.

\section{CONCLUSION}

In conclusion, noninvasive strategies probably save costs and avoid unnecessary gastroscopies; however, there are a considerable number of patients undiagnosed with these methods. In our study, platelet count, spleen size and firboscan are the best noninvasive methods. These methods can be useful in our daily practice to decide which patients could avoid a gastroscopy.

\section{BIBLIOGRAPHY:}

1. Berzigotti A, Ashkenazi E, Reverter E, Abraldes JG, Bosch J. Non-invasive diagnostic and prognostic evaluation of liver cirrhosis and portal hypertension. Disease markers, 2011; 31(3):129138.

2. Llop E, Lopez M, de la Revilla J, Fernandez N, Trapero M, Hernandez M, Fernández- Carrillo C, Pons F, Martinez JL, Calleja JL. Validation of noninvasive methods to predict the presence of gastroesophageal varices in a cohort of patients with compensated advanced chronic liver disease. Journal of gastroenterology and hepatology. 2017 Nov;32(11):1867-72.

3. Abbasi A, Butt N, Bhutto AR, Munir SM. Correlation of thrombocytopenia with grading of esophageal varices in chronic liver disease patients. J Coll Physicians Surg Pak. 2010 Jun 20;20(6):369-72..

4. Garcia-Tsao G, Sanyal AJ, Grace ND, and Carey W. Prevention and management of Gastrooesophagealvarices and varicealhaemorrhage in cirrhosis. AASLD Practice Guideline, Hepatology 2007; 46(3): 922-38.

5. D'Amico G, Pagliaro L, Bosch J. Pharmacological treatment of portal hypertension: an evidencebased approach. InSeminars in liver disease 1999 (Vol. 19, No. 04, pp. 475-505). (C) 1999 by Thieme Medical Publishers, Inc..

6. Garcia- Tsao G, Abraldes JG, Berzigotti A, Bosch J. Portal hypertensive bleeding in cirrhosis: Risk stratification, diagnosis, and management: 2016 practice guidance by the American Association for the study of liver diseases. Hepatology. 2017 Jan;65(1):310-35.

7. Amitrano L, Guardascione MA, Manguso F, Bennato R, Bove A, DeNucci C, Lombardi G, Martino R, Menchise A, Orsini L, Picascia S. The effectiveness of current acute variceal bleed treatments in unselected cirrhotic patients: refining short-term prognosis and risk factors. American Journal of Gastroenterology. 2012 Dec 1;107(12):1872-8.

8. Reverter E, Tandon P, Augustin S, Turon F, Casu S, Bastiampillai R, Keough A, Llop E, González A, Seijo S, Berzigotti A. A MELD-based model to 
determine risk of mortality among patients with acute variceal bleeding. Gastroenterology. 2014 Feb 1;146(2):412-9.

9. Fortune BE, Garcia-Tsao G, Ciarleglio M, Deng Y, Fallon MB, Sigal S, Chalasani NP, Lim JK, Reuben A, Vargas HE, Abrams G. Child-TurcottePugh Class is best at stratifying risk in variceal hemorrhage: analysis of a US multi-center prospective study. Journal of clinical gastroenterology. 2017 May;51(5):446-453

10. D'amico G, Pasta L, Morabito A, D'Amico M, Caltagirone M, Malizia G, Tinè F, Giannuoli G, Traina M, Vizzini G, Politi F. Competing risks and prognostic stages of cirrhosis: a 25- year inception cohort study of 494 patients. Alimentary pharmacology \& therapeutics. 2014 May;39(10):1180-93.

11. Scaglione S, Kliethermes S, Cao G, Shoham D, Durazo R, Luke A, Volk ML. The epidemiology of cirrhosis in the United States. Journal of clinical gastroenterology. 2015 Sep 1;49(8):690-6.

12. Sarangapani A, Shanmugam C, Kalyanasundaram M, Rangachari B, Thangavelu P, Subbarayan JK. Noninvasive prediction of large esophageal varices in chronic liver disease patients. Saudi journal of gastroenterology: official journal of the Saudi Gastroenterology Association. 2010 Jan;16(1):38.

13. Grace ND. 'Diagnosis and treatment of gastrointestinal bleeding secondary to portal hypertension', American Journal of Gastroenterology, 1997; 92(7):1081-1091.

14. Schepis F, Cammà C, Niceforo D, Magnano A, Pallio S, Cinquegrani M, D'Amico G, Pasta L, Craxì A, Saitta A, Raimondo G. Which patients with cirrhosis should undergo endoscopic screening for esophageal varices detection?. Hepatology. 2001 Feb;33(2):333-8.

15. Berzigotti A, Ashkenazi E, Reverter E, Abraldes JG, Bosch J. Non-invasive diagnostic and prognostic evaluation of liver cirrhosis and portal hypertension. Disease Markers. 2011 Jan 1;31(3):129-38.

16. Berzigotti A, Gilabert R, Abraldes JG, Nicolau C, Bru C, Bosch J, Garcia-Pagan JC. Noninvasive prediction of clinically significant portal hypertension and esophageal varices in patients with compensated liver cirrhosis. American Journal of Gastroenterology. 2008 May 1;103(5):1159-67.

17. Zaman A, Hapke R, Flora K, Rosen HR, Benner $\mathrm{K}$. Factors predicting the presence of esophageal or gastric varices in patients with advanced liver disease. The American journal of gastroenterology. 1999 Nov 1;94(11):3292-6.

18. Mueller S, Sandrin L. Liver stiffness: a novel parameter for the diagnosis of liver disease, Hepatic Medicine: Evidence and Research, 2010; 2:49-67.

19. Kim BK, Han KH, Park JY, Ahn SH, Kim JK, Paik YH, Lee KS, Chon CY. A liver stiffness measurement-based, noninvasive prediction model for high-risk esophageal varices in B-viral liver cirrhosis. American Journal of Gastroenterology. 2010 Jun 1;105(6):1382-90.

20. Berzigotti A, Seijo S, Arena U, Abraldes JG, Vizzutti F, García-Pagán JC, Pinzani M, Bosch J. Elastography, spleen size, and platelet count identify portal hypertension in patients with compensated cirrhosis. Gastroenterology. 2013 Jan 1;144(1):102-11.

21. Guha NI, Iredale, JP. Clinical and diagnostic aspects of cirrhosis. In: Rodes J, Benhamou JP, Blei A, Reichen J, Rizzetto M (eds), Textbook of hepatology from basic science to clinical practice, $3^{\text {rd }}$ edn, Oxford, Blackwell Publishers, 2007; 60422.

22. Hernandez-Gea V, Friedman SL. Pathogenesis of liver fibrosis. Annual review of pathology: mechanisms of disease. 2011 Feb 28;6:425-56.

23. D'Amico G, Garcia-Tsao G, Pagliaro L. 'Natural history and prognostic indicators of survival in cirrhosis: a systematic review of 118 studies', Journal of hepatology, 2006; 44: 217-231.

24. Ahsan T, Ahsan M, Kamal MM, Hossain KJ, Haque ME, Islam SN. Lifestyle, Nutritional Status and Seroclinical Profile of Liver Cirrhotic Patients. Bangladesh medical journal, 2007; 36(2): 44-47.

25. Mahtab MA, Rahman S, Kamal M, Shrestha A, Akbar SM, Karim F, Dhar SC. Low viral load does not exclude significant liver damage in patients with chronic HBV infection in Bangladesh. BSMMU J. 2008; 1(1): 19-21.

26. Sharma SK, Aggarwal R. Prediction of large esophageal varices in patients with cirrhosis of the liver using clinical, laboratory and imaging parameters. J Gastroenterol Hepatol. 2007; 22: 1909-15.

27. Mahfuzzaman M, Hoque MN, Ahmed S, Bhuiyan TM. Correlation between Platelet Count vs Spleen Bipolar Diameter Ratio and Esophageal Varices in Liver Cirrhosis. BIRDEM Medical Journal, 2018; 8(2):159-166.

28. Garcia-Tsao G, Sanyal AJ, Grace ND, Carey W. Prevention and management of Gastrooesophagealvarices and varicealhaemorrhage in cirrhosis. AASLD Practice Guideline, Hepatology. 2007; 46(3):922-38.

29. Giannini EG, Zaman A, Kreil A, Floreani A, Dulbecco P, Testa E, Sohaey R, Verhey P, PeckRadosavljevic M, Mansi C, Savarino V. Platelet count/spleen diameter ratio for the noninvasive diagnosis of esophageal varices: results of a multicenter, prospective, validation study. American Journal of Gastroenterology. 2006 Nov $1 ; 101(11): 2511-9$.

30. Chang YW. Indication of treatment for esophageal varices: who and when? Digestive Endoscopy. 2006; 18(1):10-15. 
31. Schepis $\mathrm{F}$, Cammà $\mathrm{C}$, Niceforo $\mathrm{D}$, Magnano $\mathrm{A}$, Pallio S, Cinquegrani M, D'Amico G, Pasta L, Craxì A, Saitta A, Raimondo G. Which patients with cirrhosis should undergo endoscopic screening for esophageal varices detection?. Hepatology. 2001 Feb;33(2):333-8.

32. Foucher J, Chanteloup E, Vergniol J, Carstera L, Bail BL, Adhoute X. Diagnosis of cirrhosis by kansient elastography (Fibroscan): a prospective study. Gut. 2006; 55:403- 408.

33. Kazemi R Kettaneh A, N'kontchou G, Pinto E, Trinchet J, Beaugrand $\mathrm{M}$, et al. Liver stiffiress measurement selects patients with cirrhosis at risk of bearing large esophageal varices. J Hepatol. 2006; 45 230-235

34. Vizzutti F, Arena U, Romanelli RG, Rega L, Foschi M, Colagrande S, Petrarca A, Moscarella S, Belli G, Zignego AL, Marra F. Liver stiffness measurement predicts severe portal hypertension in patients with HCV- related cirrhosis. Hepatology. 2007 May;45(5):1290-7.

35. Pilette C, Oberti F, Aubé C, Rousselet MC, Bedossa P, Gallois Y, Rifflet H, Calès P. Noninvasive diagnosis of esophageal varices in chronic liver diseases. Journal of hepatology, 1999; 31(5):867-873.

36. Chalasani N, Imperiale $\mathrm{T}$, Ismail A, Sood G, Wilcox CM, Kwo P, Lumeng L, Madichetty H, Carey M, Boyer TD. A predictive index for determining the risk for presence of large esophageal, varices in pateints with cirrhosis. Gastroenterology. 1998 Apr 15;114:A1222.

37. Giannini E, Botta F, Borro P, Risso D, Romagnoli P, Fasoli A, Mele MR, Testa E, Mansi C, Savarino V, Testa R. Platelet count/spleen diameter ratio: proposal and validation of a non-invasive parameter to predict the presence of oesophageal varices in patients with liver cirrhosis. Gut. 2003 Aug 1;52(8):1200-5.

38. Sen S, Griffiths WJ. Non-invasive prediction of oesophageal varices in cirrhosis. World J Gastroenterol. 2008; 14:2454-5.

39. Cherian JV, Deepak N, Ponnusamy RP, Somasundaram A, Jayanthi V. Non-invasive predictors of esophageal varices. Saudi journal of gastroenterology: official journal of the Saudi Gastroenterology Association, 2011; 17(1):64

40. Llop E, Lopez M, de la Revilla J, Fernandez N, Trapero M, Hernandez M, Fernández- Carrillo C, Pons F, Martinez JL, Calleja JL. Validation of noninvasive methods to predict the presence of gastroesophageal varices in a cohort of patients with compensated advanced chronic liver disease. Journal of gastroenterology and hepatology. 2017 Nov;32(11):1867-72.

41. Thomopoulos KC, Labropoulou-Karatza C, Mimidis KP, Katsakoulis EC, Iconomou G, Nikolopoulou VN. Non- invasive predictors of the presence of large oesophageal varices in patients with cirrhosis. Dig Liver Dis. 2003; 35:473-8. 